Александр В. Саленко, Яня В. Мулярчик

Baltycki Federalny Uniwersytet im. I. Kanta

Uniwersytet w Bialymstoku

\title{
СВОБОДА СОБРАНИЙ В БЕЛОРУССИИ И РОССИИ: СРАВНИТЕЛЬНО-ПРАВОВОЙ АНАЛИЗ ${ }^{1}$
}

\section{І. Введение}

В Москве 8 декабря 1999 года был подписан Договор о Создании Союзного Государства Республики Беларусь и Российской Федерации. ${ }^{2}$ К числу главных целей Союзного Государства Беларусси и России (далее как СГБР) относятся обеспечение мирного и демократического развития братских народов государств-участников СГБР, укрепление дружбы, повышение благосостояния и уровня жизни; неуклонное соблюдение основных прав и свобод человека и гражданина в соответствии с общепризнанными принципами и нормами международного права; формирование единой правовой системы демократического государства; проведение согласованной социальной политики, направленной на создание условий, обеспечивающих достойную жизнь и свободное развитие человека (ч.1 ст.2 Договора о Создании Союзного Государства). Таким образом, помимо всего прочего в основу союзной интеграции была положена общая правовая политика, направленная на гармонизацию внутреннего законодательства государств-участников СГБР. В качестве стратегической цели декларируется создание единой правовой системы СГБР. Подобная де-

Данная статья подготовлена в рамках научно-исследовательского проекта на факультете права университета города Белосток, финансируемого фондом поддержки науки / фондом имени И. Мяновского (Jozef Mianowski Fund / A Foundation for the Promotion of Science - the Fellowship Program Research \& Experience). Саленко А.В. статьи выражает свою благодарность коллегам на факультете права в Белостоке, а также сотрудникам фонда И.Мяновского в Варшаве за их поддержку и поддержку во время работы над данным материалом. Особая благодарность Яне Владимировне Мулярчик (соавтору настоящей статьи), согласившейся участвовать в совместной работе над данной статьёй, которой удалось обобщить и проанализировать интересный материал о внутригосударственном законодательстве и правоприменительной практике в Республике Беларусь.

2 Договор о Создании Союзного Государства Республики Беларусь и Российской Федерации от 8 декабря 1999 года // Информационно-аналитический портал Союзного государства - http://www.soyuz.by/ $\mathrm{ru} /$ ?guid=10447 
кларация подразумевает собой унификацию правового регулирования в сфере защиты прав и свобод человека. В рамках данного сравнительно-правового исследования предпринята попытка сопоставить действующие юридические нормы, регулирнющие публичные собрания в Беларуссии и России, и сделать выводы о том, в каком направлении должна развиваться дальнейшая работа государств-участников СГБР по совершенствованию правового регулирования свободы собраний.

\section{II. Источники права регулирующие проведение публич- ных собраний в Беларуси и в России}

Правовые системы Беларуси и России основаны на принципе примата международного права над внутригосударственным (национальным) правовым регулированием. Конституция Республики Беларусь ${ }^{3}$ (далее как КРБ) закрепляет, что Беларусь признает приоритет общепризнанных принципов международного права и обеспечивает соответствие им национального законодательства (ч.1 ст.8 КРБ). Аналогичное правовое регулирование содержит ч. 4 ст. 15 Конституции Российской Федерации ${ }^{4}$ (далее - КРФ): общепризнанные принципы и нормы международного права и международные договоры Российской Федерации являются составной частью ее правовой системы. Если международным договором Российской Федерации установлены иные правила, чем предусмотренные законом, то применяются правила международного договора. Однако есть малый, но важный нюанс, отличающий конституционно-правовое закрепление принципа приоритета международного права над внутригосударственным правом в Основном Законе Беларуссиию Там прямо указывается на недопустимость заключения международных договоров, которые противоречат Конституции Республики Беларусь (ч.3 ст.8 КРБ). Подобное конституционно-правовое регулирование отсутствует в Основном Законе Российской Федерации.

Важной общей международно-правовой основой права проведения публичных собраний как в Беларуссии, так и в России являются положения Всеобщей декларации прав человека (ч.1 ст.20), а также Международного пакта о гражданских и политических правах (далее как МПГПП), в соответствии с которыми признается право на мирные собрания. Пользование этим правом

\footnotetext{
3 Конституция Республики Беларусь 1994 года (с изменениями и дополнениями, принятыми на республиканских референдумах 24 ноября 1996 г. и 17 октября 2004 г.) // Национальный правовой интернет-портал Республики Беларусь - http://www.pravo.by/main.aspx?guid=3871\&p0=v19402875\&p2=\%7BNRPA\%7D (Constitution of the Republic of Belarus in English: http://www.president.gov.by/en/press10669.html).

4 Конституция РФ 1993 года // http://constitution.kremlin.ru/ (The Constitution of the Russian in English - http:// eng.constitution.kremlin.ru/)
} 
не подлежит никаким ограничениям, кроме тех, которые налагаются в соответствии с законом и которые необходимы в демократическом обществе в интересах государственной или общественной безопасности, общественного порядка, охраны здоровья и нравственности населения, защиты прав и свобод других лиц (ст.21 МПГПП). В силу того факта, что Российская Федерация является государством-членом Совета Европы, российское право публичных собраний основывается также на положениях части 1 статьи 11 Европейской конвенции о защите прав человека и основных свобод, которая устанавливает право каждого человека на свободу мирных собраний.

C учётом положений указанных международно-правовых документов было сформировано внутригосударственное законодательство о свободе собраний в государствах-участниках СГБР. В Республике Беларусь свобода собраний, митингов, уличных шествий, демонстраций и пикетирования, не нарушающих правопорядок и права других граждан, гарантируется государством (ст.35 КРБ). Порядок проведения указанных мероприятий определяется отдельным законом. В 1997 году был принят Закон Республики Беларусь «О массовых мероприятиях в Республике Беларусь» ${ }^{5}$, в который белорусским законодателем многократно вносились изменения и дополнения. В Основном Законе Российской Федерации также устанавливается лишь общее (рамочное) правовое регулирование свободы собраний: граждане Российской Федерации имеют право собираться мирно, без оружия, проводить собрания, митинги и демонстрации, шествия и пикетирование (ст.31 КРФ). Детализацию данных конституционно-правовых положений содержит отдельный специальный закон: Федеральный закон РФ от 19 июня 2004 г. N 54-Ф3 «О собраниях, митингах, демонстрациях, шествиях и пикетированиях» ${ }^{6}$, который также неоднократно подвергался изменениям и дополнениям со стороны российского законодателя.

\section{III. Порядок организации публичных мероприятий в Беларуссии}

Белорусский закон о свободе собраний (ч.2 ст.6) устанавливает разрешительный порядок проведения массовых мероприятий. В соответствии с законом (ст.4), организаторами собрания, митинга, уличного шествия, демонстрации и пикетирования которое рассчитано на число демонстрантов до тысячи

5 Закон Республики Беларусь от 30 декабря 1997 г. № 114-3 «О массовых мероприятиях в Республике Беларусь» // Национальный правовой интернет-портал Республики Беларусь - http://pravo.by/main.aspx?guid $=3871 \& \mathrm{p} 0=\mathrm{h} 19700114 \& \mathrm{p} 2=\% 7 \mathrm{bNRPA} \% 7 \mathrm{~d}$

6 Федеральный закон от 19 июня 2004 г. N 54-Ф3 «О собраниях, митингах, демонстрациях, шествиях и пикетированиях» (с изменениями и дополнениями) // СПС «Гарант» - http://base.garant.ru/12135831/ 
человек, могут являться граждане Республики Беларусь, постоянно проживающие на её территории, достигшие восемнадцатилетнего возраста и обладающие избирательным правом, а также политические партии, профессиональные союзы и иные организации, зарегистрированные в установленном порядке. В том случае, если массовое мероприятие предполагает участие свыше тысячи человек, то их организаторами могут выступать лишь политические партии, профессиональные союзы и другие организации Республики Беларусь.

Согласно требованиям закона организатор (организаторы) массового мероприятия должен (должны) предоставить в письменной форме заявление о проведении мероприятия не позднее, чем за пятнадцать дней до намеченной даты проведения собрания, митинга, уличного шествия, демонстрации или пикетирования. В соответствии с законом (ст.6), руководитель местного исполнительного и распорядительного органа или его заместитель обязаны рассмотреть заявление и не позднее чем за пять дней до даты проведения массового мероприятия в письменной форме сообщить его организатору (организаторам) о принятом решении. В решении должно быть указано на разрешение или запрещение проведения массового мероприятия, а также мотивы, по которым его проведение запрещено. Решение, которое принял руководитель местного исполнительного (распорядительного) органа или его заместитель о запрещении собрания, митинга, уличного шествия, демонстрации и пикетирования, может быть обжаловано в суд.

В соответствии с законом (ст.9), публичные мероприятия могут проводиться в любых пригодных для этих целей местах, исключая места использование которых запрещено решениями местных исполнительных (распорядительных органов). Кроме того, местные исполнительные и распорядительные органы могут определять постоянные места для проведения собраний, митингов, уличных шествий, демонстраций и пикетирования, а также места, где проведение указанных выше мероприятий не допускается. Закон устанавливает допустимое время для проведения собраний, митингов, уличных шествий, демонстраций и пикетирования: с 8 до 22 часов.

Особая специфика права публичных собраний Беларуссии заключается в том, что на граждан, являющихся организаторами мирных собраний, законом (ст.6) фактически возлагаются дополнительные обязанности по заключению договоров на возмездной основе с отделами внутренних дел по охране общественного порядка во время проведения массового мероприятия, с медицинскими учреждениями (для медицинского обслуживания лиц участников эти мероприятий) и с коммунальными службами, которые должны обеспечить уборку территории после проведения на ней мирного собрания. 


\section{IV. Организация публичных мероприятий в России}

В России действует уведомительный порядок проведения публичных мероприятий. В соответствии с российским законом (ч.1 ст.5), организатором публичного мероприятия могут быть один или несколько граждан Российской Федерации (организатором демонстраций, шествий и пикетирований - гражданин Российской Федерации, достигший возраста 18 лет, митингов и собраний - 16 лет), политические партии, другие общественные объединения и религиозные объединения, их региональные отделения и иные структурные подразделения, взявшие на себя обязательство по организации и проведению публичного мероприятия.

Уведомление о проведении публичного мероприятия (за исключением собрания и пикетирования, проводимого одним участником) подается его организатором в письменной форме в орган исполнительной власти субъекта Российской Федерации или орган местного самоуправления в срок не ранее 15 и не позднее 10 дней до дня проведения публичного мероприятия. При проведении пикетирования группой лиц уведомление о проведении публичного мероприятия может подаваться в срок не позднее трех дней до дня его проведения, а если указанные дни совпадают с воскресеньем и (или) нерабочим праздничным днем (нерабочими праздничными днями), - не позднее четырех дней до дня его проведения. Уведомление о пикетировании, осуществляемом одним участником, не требуется. Однако закон устанавливает минимальное допустимое расстояние между лицами, осуществляющими указанное одиночное пикетирование, которое не может быть более пятидесяти метров.

В соответствии с законом (ч.1 ст.8) публичное мероприятие может проводиться в любых пригодных для целей данного мероприятия местах в случае, если его проведение не создает угрозы обрушения зданий и сооружений или иной угрозы безопасности участников данного публичного мероприятия. Кроме того, органы исполнительной власти субъекта Российской Федерации определяют единые места специально отведенные или приспособленные для коллективного обсуждения общественно значимых вопросов и выражения общественных настроений, а также для массового присутствия граждан для публичного выражения общественного мнения по поводу актуальных проблем преимущественно общественно-политического характера места. Порядок использования специально отведенных мест, нормы их предельной заполняемости и предельная численность лиц, участвующих в публичных мероприятиях, уведомление о проведении которых не требуется, устанавливаются законом субъекта Российской Федерации. При этом указанная предельная численность не может быть менее ста человек. 
Согласно российскому законодательству публичное мероприятие не может начинаться ранее 7 часов и заканчиваться позднее 22 часов текущего дня по местному времени, за исключением публичных мероприятий, посвященных памятным датам России, публичных мероприятий культурного содержания.

\section{V. Особенности правоприменения законодательства о свободе собраний в Республике Беларусь и Российской Федерации: выводы и рекомендации}

Основываясь на положениях международного права, приоритет которого признают государства-участники СГБР, следует сделать вывод о том, что положения их внутригосударственного права чрезмерно ограничивают круг субъектов права на свободу собраний. В частности, право на организацию и проведение публичных мероприятий закрепляется в законодательстве Беларуссии и России исключительно за гражданами отдельного государства. В то время как положения международных договоров, подписанных государствами-участниками СГБР, закрепляют, что право на мирные собрания есть у каждого человека. Помимо этого основой СГБР является признание равных прав и свобод за гражданами Союзного Государства. Однако, исходя из положений внутригосударственных законов о публичных мероприятий, следует сделать вывод о том, что этого равенства граждан Республики Беларусь и Российской Федерации в законодательном порядке закреплено не было.

В процессе сравнения действующего законодательства о публичных мероприятиях в государствах-участниках СГБР становится ясно вывод о том, что российское право публичных собраний более либерально по сравнению с соответствующими нормами белорусского закона. Опять же, учитывая стратегические цели СГБР, в частности создание единой правовой системы СГБР, следует стремиться к тому, чтобы гармонизировать нормы права, регулирующие проведение публичных собраний в Беларуссги и в России.

Можно согласиться с критикой белорусского законодательства ${ }^{7}$ в той части, что закон Беларуссии о публичных мероприятиях «характеризуется подробным сверхрегулированием процедурных аспектов проведения собраний», а также что данный «закон создает сложную процедуру согласования, оставляя в то же время широкие полномочия административным властям в том, как применить этот закон. Эта процедура не соответствует обязательствам государства гарантировать и облегчить осуществление права на свободу собраний».

Joint opinion on the law on mass events of the Republic of Belarus adopted by the Venice Commission at its 90th Plenary Session (Venice, 16-17 march 2012) // http://www.venice.coe.int/webforms/ documents/?country=26\&year=all 
В этом контексте представляются излишними (в демократическом обществе) требования белорусского законодательства в адрес организаторов массовых мероприятий по оплате охраня общественного порядка при их проведении, а также медицинского обслуживания участников мероприятия и услуг коммунальных служб по уборке места проведения массового мероприятия. О необходимости отмены данной обязанности организаторов убедительно говорит тот факт, что все граждане Беларуси посредством уплаты соответствующих налогов и сборов непосредственно участвуют в содержании органов правопорядка, медицинских учреждений и коммунальных служб. Подобная двойная оплата «услуг» представляется неуместной не только с позиций публичного, но и частного права.

Можно также согласиться с выводом международных экспертов, Право публичных собраний государств-участников СГБР «...фактически делает незаконными любые спонтанные акции. ...содержит много ограничений по времени и месту проведения акций, а также неправомерно устанавливает ограничения для того, кто может быть организатором собрания». В этом отношении право публичных собраний и Беларуссии и России обладает общими недостатками, которые следует устранять посредством законотворческой работы и соответствующей корректировки правоприменительной практики.

Безусловно, законодательство государств-участников СГБР всё еще далеко от совершенства. Можно лишь надеяться, что работа по улучшению действующего права публичных собраний будет продолжена в ближайшие годы законодателями Беларуссти и России. При этом следует высказать рекомендацию как законодателями, так и правоприменителям государств-участников СГБР: почаще вспоминать о существовании Союзного Государства Беларуссии и России, в рамках которого правовые системы двух стран должны быть подвержены гармонизации, в том числе и право публичных собраний должно модернизироваться. В рамках данной работы следует учитывать и существующий опыт каждого государства-участника. Например, решения Конституционного Суда России о том, что государственным властям необходимо отказаться от привлечения к административной ответственности организаторов публичного мероприятия в том случае, если на мероприятие фактически приходит больше участников, чем было заявлено в уведомлении. ${ }^{8}$ Помимо этого в 2013 году Конституционный суд России сделал вывод о том, что необходимо предоставить только органам судебной власти определение пределов ответственно-

8 Постановление Конституционного Суда РФ от 18.05.2012 N 12-П «По делу о проверке конституционности положений части 2 статьи 20.2 Кодекса Российской Федерации об административных правонарушениях, пункта 3 части 4 статьи 5 и пункта 5 части 3 статьи 7 Федерального закона «О собраниях, митингах, демонстрациях, шествиях и пикетированиях» в связи с жалобой гражданина С.А. Каткова» // СПС «КонсультантПлюс» - http://base.consultant.ru/cons/cgi/online.cgi?req=doc;base=LAW;n=130163 
сти организаторов публичного мероприятия. ${ }^{9}$ Фактически судьи Конституционного Суда РФ снизили размер штрафов за нарушение административного законодательства в ходе публичных мероприятий. ${ }^{10}$ И последнее, но не менее важноеобстоятельства - это практика Европейского суда по правам человека в Страсбурге, который констатировал нарушение со стороны публичных властей права граждан на свободу мирных собраний, в частности посредством устанавления фактический невозможности проведения мирных контрдемонстраций или публичных мероприятий, на которых высказываются непопулярные или даже шокирующие, неприемлемые для большинства взгляды. ${ }^{11}$

Таким образом, взаимный законодательный и правоприменительный опыт, а также международная судебная практика должны стать основой для работы по совершенствованию права публичных собраний, действующего в рамках Союзного Государства Беларуси и России, главной целью которого является неуклонное соблюдение основных прав и свобод человека и гражданина, формирование единой правовой системы и создание условий, обеспечивающих достойную жизнь и свободное развитие человека (ч.1 ст.2 Договора о Создании Союзного Государства).

\section{БИБЛИОГРАФИЯ}

1. Договор о СозданииСоюзногоГосударстваРеспубликиБеларусь и РоссийскойФедерацииот 8 декабря 1999 года // Информационно-аналитическийпорталСоюзногогосударства.

2. Федеральныйзаконот 19 июня 2004 г. N 54-Ф3 «О собраниях, митингах, демонстрациях, шествиях и пикетированиях» (с изменениями и дополнениями) // СПС «Гарант»

3. Храмова Т.М. Правонаконтрдемонстрации: угрозаилииндикаторуровнядемократии? // Конституционное и муниципальноеправо. 2012. № 7.

4. КонституцияРеспубликиБеларусь 1994 года (с изменениями и дополнениями, принятыминареспубликанскихреферендумах 24 ноября 1996 г. и 17 октября 2004 г.) // Национальныйправовойинтернет-порталРеспубликиБеларусь

5. Свободамирныхсобраний: европейскиестандарты и законодательствоРеспубликиБеларусь / пер. ст. А.Е. Вашкевича, В.В. Филиппова ; науч. ред. А.Е. Вашкевич ; отв. ред. В.В. Филиппов. - Минск : Тесей, 2009.

6. ЗаконРеспубликиБеларусьот 30 декабря 1997 г. № 114-3 «О массовыхмероприятиях в РеспубликеБеларусь» // Национальныйправовойинтернет-порталРеспубликиБеларусь.

9 Постановление Конституционного Суда РФ от 14.02.2013 N 4-П «По делу о проверке конституционности Федерального закона «О внесении изменений в Кодекс РФ об административных правонарушениях и Федеральный закон «О собраниях, митингах, демонстрациях, шествиях и пикетированиях» в связи с запросом группы депутатов Государственной Думы и жалобой гражданина Э.В. Савенко» // СПС « КонсультантПлюс» - http://www.consultant.ru/law/hotdocs/24001.html

10 Закон о митингах скорректировали / Информационное агентство «ИНТЕРФАКС / INTERFAX» - http://www. interfax.ru/russia/txt.asp?id=290601

11 Храмова Т.М. Право на контрдемонстрации: угроза или индикатор уровня демократии? // Конституционное и муниципальное право. 2012. № 7. С. 10-16. 
THE FREEDOM OF ASSEMBLY IN BELARUS AND RUSSIA: A COMPARATIVE STUDY

The authors of the article undertake a comparative study of the existing legislation of Belarus and Russia on the Freedom of Assembly. The focus point of the research paper is concentrated on the investigation of practical problems of the Public Protest Law in the Union State of Belarus and Russia founded in 1999. One of the declared aims of the Union State is the harmonization of legal systems of member-states. Taking into account this declaration, the authors of the article provide recommendations regarding further liberalisation of the Public Assembly Law in Belarus and Russia. The authors arrive at the conclusion that the legislative activities in the field of the Public Protest Law in the Union State of Belarus and Russia should be continued in the nearest future.

Key words: demonstration, meeting, public protest law, freedom of assembly, Belarus, Russia, the Union State. 